\title{
Julian Davies and the discovery of kanamycin resistance transposon $\operatorname{Tn} 5$
}

\author{
Douglas E Berg
}

This paper recounts some of my fond memories of a collaboration between Julian Davies and myself that started in 1974 in Geneva and that led to our serendipitous discovery of the bacterial kanamycin resistance transposon Tn5, and aspects of the lasting positive impact of our interaction and discovery on me and the community. Tn 5 was one of the first antibiotic resistance transposons to be found. Its analysis over the ensuing decades provided valuable insights into mechanisms and control of transposition, and led to its use as a much-valued tool in diverse areas of molecular genetics, as also will be discussed here. The Journal of Antibiotics (2017) 70, 339-346; doi:10.1038/ja.2016.120; published online 12 October 2016

\section{BACKGROUND}

It was wonderfully educational, productive and exciting for me to work with Julian Davies for a few years in the mid 1970s, doing experiments that led to the serendipitous discovery and initial characterizations of kanamycin resistance transposon $\operatorname{Tn} 5^{1}$-one of the first and most useful of the many bacterial antibiotic resistance (AR) transposons that have been found. ${ }^{2}$ I was inspired by Julian's knowledge of mechanisms of antibiotic action and resistance mechanisms, his creativity and clarity of thought and expression, as illustrated in his numerous papers, ${ }^{3-6}$ and by his high energy, kindness and inventive good humor-traits that have enriched the lives and careers of many people over the years. Described here, in tribute to Julian and his special character, are my memories of a collaboration that led to Tn5's unexpected discovery, Tn5's properties, and some lasting impacts of our collaboration on the field and on me personally.

We began interacting in 1974, soon after Julian arrived in Geneva to begin his sabbatical with Pierre Francois Spahr (Department of Molecular Biology of the University). ${ }^{7}$ I was then in my fourth (final) year as Chargé de Recherche (senior postdoc) in Lucien Caro's group in the same department, studying $\lambda d v$ plasmids, often in collaboration with Grete Kellenberger-Gujer, also in Lucien's group ${ }^{8-13}$-and during these years, also hugely enjoying features in and out of the lab that have drawn researchers to Geneva for decades: a superb scientific atmosphere, year-round easy access to the exquisite Alps and Jura mountains, and the language, cuisine and culture of Geneva and vicinity. I had become intrigued the year before by Julian's ideas about origins and evolution of resistance genes, as described in his paper with Raoul Benveniste. ${ }^{14}$ They advanced the then-novel theory that the types of bacteria that had provided life saving antibiotics were also the ancestral sources of AR genes that were becoming increasingly common in human and veterinary pathogens. Their inferences were based on finding aminoglycoside modifications-neomycin and/or streptomycin phosphorylation and gentamicin and neomycin acetylation-in extracts of several antibiotic producing bacterial strains that were identical to modifications produced by certain $\mathrm{R}$ (resistance) factor plasmid-encoded enzymes. ${ }^{14}$

\section{$\lambda d v$ AND Tn5's DISCOVERY}

The discovery of $\operatorname{Tn} 5$ was a totally unanticipated and hugely exciting outgrowth of my $\lambda d v$ studies with Grete, and of my discussions with Julian that had encouraged me to think about making AR gene marked $\lambda d v$ plasmids. Initially my primary reason for making $\lambda d v$-AR plasmids was to be able to better analyze $\lambda d v$ regulation and interactions with host cells. ${ }^{10}$ In brief, $\lambda d v$ s are small multicopy plasmids that were discovered by Kenichi Matsubara and Dale Kaiser ${ }^{8}$ and that derive from phage $\lambda$ by deletion of the $\geqslant 90 \%$ of its genome that is not needed for controlled DNA replication (for example, deletion of genes for integration into the bacterial chromosome, virus particle assembly and cell lysis). $\lambda d v$ 's most intriguing property was its inhibition of lytic growth of superinfecting $\lambda$ phage-even $\lambda v i$, whose mutant repressor binding sites allows it to grow lytically in standard $\lambda$ lysogens. ${ }^{8}$ Inhibition involves near-complete shutoff of expression of most phage genes, thereby reducing the infecting phage DNA to a plasmid state. This virus-plasmid state is unstable in that, in a small fraction of $\lambda d v$ carriers the inhibited phage DNAs are lost as cells grow and divide, and that in another small fraction of $\lambda d v$ carriers the phage escape inhibition sufficiently to grow lytically, produce progeny phage particles and lyse their host cells. ${ }^{10}$ This $\lambda d v$-imposed 'pseudo-immunity' was also intriguing to us in resembling, at least formally, a pseudo-immunity exerted by certain deleted derivatives of some eukaryotic viruses called 'defective interfering' particles. ${ }^{15}$

This paper is dedicated to Professor Julian Davies for inclusion in a special issue of the Journal of Antibiotics that celebrates his life in science, his great creativity and his many scientific contributions. 
As a beginning postdoc in Dale's lab, I had figured out how to select new $\lambda d v$ plasmids of various genotypes efficiently based on the pseudo-immunity they exerted. ${ }^{9,10,16}$ In Geneva we began testing a model in which pseudo-immunity involved the same factors and processes that underlie the stable well-regulated replication of $\lambda d v$ itself. In discussions with Julian I decided it would be valuable to have AR gene-marked $\lambda d v$ s so that $\lambda d v$ carriage could be selected directly by drug resistance, and thereby models of $\lambda d v$-imposed pseudo-immunity tested robustly. In addition, any resistance gene captured in a small multicopy plasmid should be useful for tests of his ideas about AR gene origins and evolution, and for analyzing resistance mechanisms. This decision soon led to Tn5's unexpected discovery.

\section{STRATEGY FOR IN VIVO CONSTRUCTION OF $\lambda d v$-AR PLASMIDS VIA $\lambda$-AR PHAGE INTERMEDIATE}

Julian and I began working together in the 'pre-dawn' of what would soon become a molecular biology revolution that would be made possible by availability of reagents and protocols for easy in vitro recombinant DNA cloning. However, in 1974 only a very few labs possessed any purified restriction endonuclease, DNA ligase, convenient plasmid vector or DNA cloning protocol, ${ }^{17-19}$ and no commercial suppliers of these needed reagents and protocols had yet appeared. Not at all realizing how soon in vitro recombinant DNA technology would become widely available, I settled on a plan for making $\lambda d v$-AR plasmids in vivo via an $\mathrm{AR}$ gene-carrying $\lambda$ phage intermediate, also to be made in vivo. My plan for $\lambda d v$-AR construction was encouraged by my success while at Stanford in making $\lambda d v$ carrying galactose utilization genes from an unusual $\lambda$ gal transducing phage. ${ }^{20}$

The planned construction of $\lambda$-AR phage was based on the discovery ${ }^{21}$ that $\lambda$ can lysogenize $E$. coli lacking its preferred integration site, attB, albeit inefficiently ( $0.05 \%$ of normal frequency), by integrating at any of the E. coli genome's hundreds of somewhat related sequences ('secondary attachment sites'). ${ }^{21}$ A small fraction of progeny phage formed by $\lambda$ induction from any integration site are variants carrying bacterial genes that had been adjacent to the prophage. These bacterial genes are typically present as substitutions, replacing phage DNA that had been next to $\lambda$ 's attP site. ${ }^{21}$ These discoveries had been used with great success for in vivo cloning many different $E$. coli genes into $\lambda$.

Assuming that secondary attB sites also would be near AR genes, we transferred several $\mathrm{R}$ factors into a $\triangle a t t B$ strain of $E$. coli as targets for $\lambda$ integration-in particular: JR72, which encodes an aminoglycoside phosphotransferase designated NPTI or APH(3')-I that confers resistance to kanamycin, neomycin and several structurally related compounds; $;^{21-23}$ and the unrelated $\mathrm{R}$ factor JR67, whose more recently discovered and unusual phosphotransferase, NPTII or APH (3')-II, ${ }^{24,25}$ was distinctive in also phosphorylating butirosin. No information was then available concerning possible DNA/protein sequence relatedness of these two NPTs to one another, and certainly not to phosphotransferases from any antibiotic producing microbes. These two $\mathrm{R}$ factors soon yielded the kanamycin resistance transposons Tn6 and Tn5, respectively, as described below.

To select $\lambda$-AR phage, large populations of these $\mathrm{R}$ factor-containing $\triangle a t t B$ strains were infected with a special $\lambda$ phage strain called $\lambda b b^{1}$

(i) whose $c I$ prophage repressor is temperature sensitive (cI857, active at 30C, inactive at 42C); (ii) that has about $\sim 4 \mathrm{~kb}$ less DNA than $\lambda$ wild type due to the deletions $\Delta b 515$ and $\Delta b 519$ (designated ' $b b$ '), which do not affect $\lambda$ growth or lysogenization (because the $\lambda$ virion's maximum DNA capacity is only slightly larger than $\lambda$ wild type's genome, these $b b$ deletions allow more bacterial DNA to be captured in viable transducing phage than is possible using $\lambda$ wild type); and (iii) $S$ am7, a nonsense mutant allele of $S$, a $\lambda$ gene needed for cell membrane disruption and thereby cell lysis. ${ }^{1}$ Use of this $S$ allele and E. coli hosts lacking the appropriate suppressor transfer RNA allows preparation of extremely high titer phage stocks by centrifugation to concentrate phage-laden bacteria at the end of the lytic cycle, and then cell lysis with chloroform.

The R factor-containing $\Delta a t t B$ strains were infected with $\lambda \mathrm{bb}$ under conditions favoring lysogenization (high multiplicity, 30C) in broth cultures, as recommended; ${ }^{21}$ lytic development was induced a few hours later by a $30-42 \mathrm{C}$ temperature shift; the billions of $\lambda b b$ phage obtained were used to infect (lysogenize) a normal attB-containing E. coli strain; and cells were spread at high density on kanamycincontaining agar to select rare transductant colonies. To our delight many such colonies were obtained; a large fraction of them yielded phage after $42 \mathrm{C}$ induction that could again transduce kanamycin resistance to new host E. coli cells. ${ }^{1}$

\section{$\lambda b b$ kan PHAGE CHARACTERIZATION}

Preliminary genetic experiments ${ }^{1}$ indicated that the kanamycin resistance trait of transducing phage whose AR gene segment was from JR72 (encoding NPTI), represented by ' $\lambda b b$ kan-3', is unstable: nearly $10 \%$ of phage obtained by induction of lysogens, and more than $60 \%$ of phage from 'plate stocks' (which involve $\sim 10$ sequential cycles of lytic growth from a single purified phage plaque) could not transduce the kanamycin resistance trait. In contrast, the resistance determinants of phage whose AR segments were from JR67 (NPTII), represented by ' $\lambda b b$ kan-1' and ' $\lambda b b$ kan-2', ${ }^{1}$ were much more stable: only about $1 \%$ phage in plate stocks did not transduce kanamycin resistance. ${ }^{1}$

Julian and I were most fortunate that Jean-David Rochaix and Bernard Allet, who had just recently joined the department faculty, each took keen interest in our results. They had come with newly acquired expertise in electron microscope DNA heteroduplex mapping (Jean-David) and DNA mapping using restriction endonucleases along with the first purified EcoRI and HindIII enzymes in Switzerland (Bernard). Being innately curious, and interactive and generous with their time and expertise, they offered to examine the DNAs of several of our purified high titer $\lambda b b$ kan phage stocks.

Their results showed unequivocally that, contrary to initial predictions (based on Shimada et al. papers ${ }^{21}$ ), none of the new $\mathrm{R}$ factor DNA segments were located next to attP nor within limits of detection $(\sim 50 \mathrm{bp})$ was any of them associated with loss of any $\lambda$ DNA. In addition, the DNAs inserted in $\lambda b b$ kan- 1 and $\lambda b b$ kan-2 (encoding NPTII, from JR67) were identical in size $(\sim 5.5 \mathrm{~kb})$ and consisted of a $\sim 1.5 \mathrm{~kb}$ inverted repeat flanking a $\sim 2.5 \mathrm{~kb}$ central region. No such inverted repeat was present in $\lambda b b$ kan-3 (NPTI, from JR72). These features are shown graphically in Jean-David's electron microscope DNA heteroduplex images (Figure 1) of a single DNA strand of $\lambda b b$ kan-1 DNA (panel a); and of annealed single DNA strands from $\lambda b b$ kan-1 and $\lambda$ wild type (panel b). In the heteroduplexes (panels b and c) single-strand loops at sites of $\Delta b 515$ and $\Delta b 519$ deletions serve as internal markers of known position. Never have I been so pleased, indeed excited, to have my predictions disproven!

\section{IMMEDIATE IMPLICATIONS OF kan INSERT MAPPING, AND EARLY TRANSPOSABLE ELEMENT HISTORY}

Jean-David's and Bernard's physical mapping immediately suggested that the resistance determinants in our $\lambda b b$ kan phage were components of transposable elements. This made them among the very first naturally drug resistance 'transposons' to be found. This was exciting 

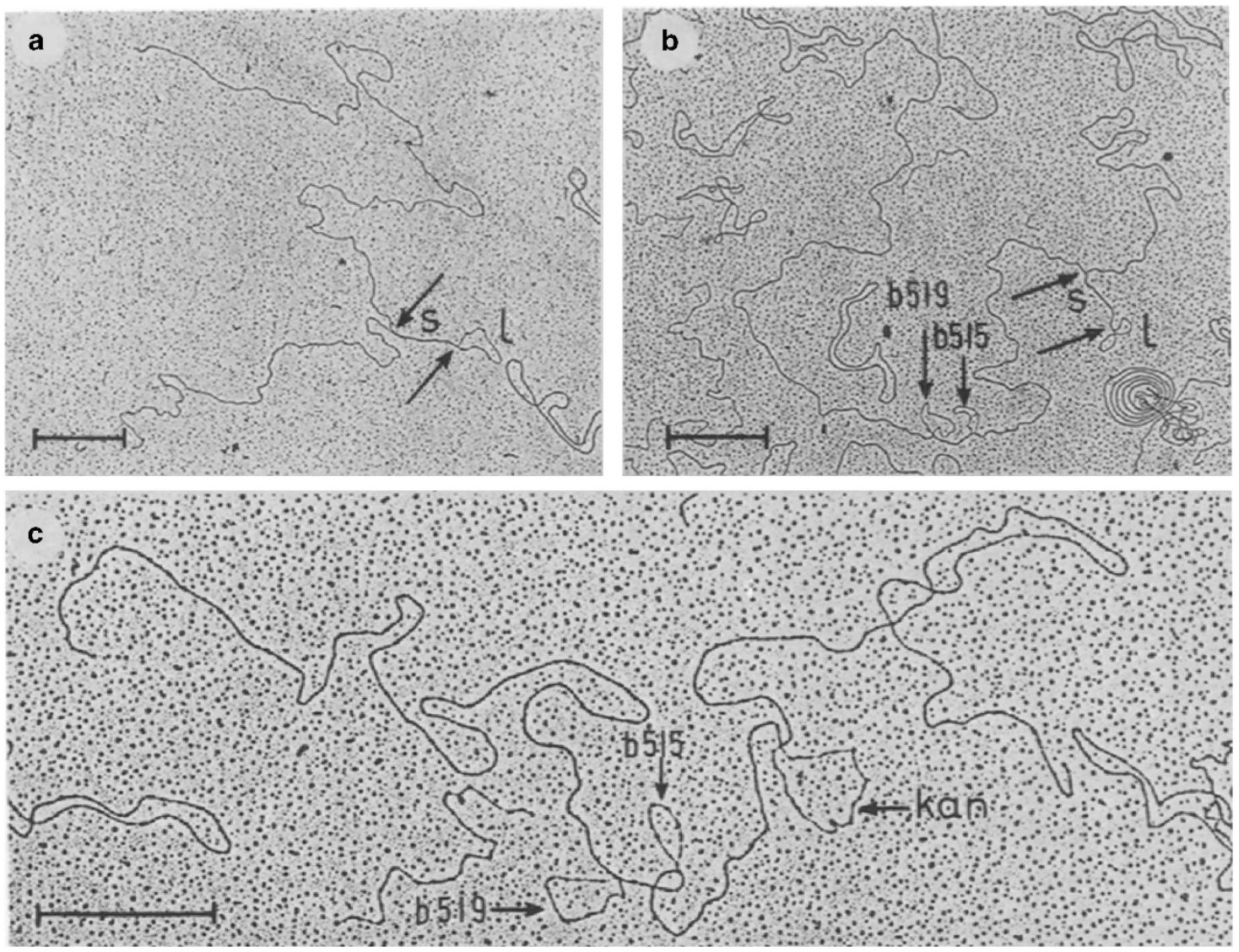

Figure 1 Electron microscope analyses of DNAs from $\lambda b b$ kan phages (reproduced from reference 1 with permission). (a) Single-stranded DNA of $\lambda b b$ kan- 1 displaying a double stranded stem (S), corresponding to $1.5 \mathrm{~kb}$ inverted repeats, flanking a central (unique sequence) region (L), a DNA segment that was soon to be called transposon Tn5 (see text). (b) Electron microscope heteroduplex (EMHD) analyses of $\lambda b b$ kan-1 DNA annealed with $\lambda$ wild-type DNA. Inspection of the junction between the inverted repeats and phage target DNA indicates that this element had inserted cleanly into the $\lambda$ DNA target, without any significant loss of $\lambda$ DNA. The single-stranded loops corresponding to sites of the $b 519$ and $b 515$ deletions provide physical reference points for identifying the site of transposon insertion. (c) EMHD analyses of $\lambda b b$ kan-3 DNA annealed with $\lambda$ wild-type DNA. Inspection of the junction between this inserted DNA segment and phage target DNA indicates that this segment (soon to be called Tn6; see text below) also had inserted cleanly into the $\lambda$ DNA target, without any significant loss of $\lambda$ DNA.

in several contexts: (i) in providing AR genes in a small, readily purified, genetically manipulatable DNA ( $\lambda$ 's genome) for studies of mechanisms, specificities and evolution of resistance enzymes-questions that had originally drawn me to Julian and his ideas and research; (ii) in suggesting another way that AR genes can spread naturally among unrelated bacterial species-that is, via transposition, in addition to $\mathrm{R}$ factor plasmid transfer or DNA transformation; and (iii) in opportunities a transposable element containing a selectable marker (resistance) would provide for analyses of the transposition phenomenon, and perhaps also as a tool for molecular genetics, in particular mutational tagging of other genes of interest in bacterial genomes.

Regarding this last point, there had been great interest in transposition phenomena since Barbara McClintock discovered mobile 'controller elements' in maize (corn). ${ }^{26-28}$ She had detected these elements in plants that had undergone cycles of chromosome breakage during their growth-events that seemed to activate these otherwise quite latent elements in the corn genome. Her discovery was based solely on her powers of keen observation and sophisticated, formal genetic (plant breeding) analysis, without benefit of any of the now standard (nearly seven decades later) molecular biology reagents and methods. The movement or 'changes of state' of such elements located near pigmentation genes often resulted in leaf and/or kernel color variegation equivalent to the variegation seen in decorative 'Indian Corn'. She proposed that such elements were likely important mediators of gene regulation and normal development in plants and animals. ${ }^{26-28}$ The idea of transposable controller elements had met with some skepticism initially. However, her concept has become widely accepted in recent decades, especially following discoveries of the great abundance of retrovirus-like elements and other repetitive DNAs in eukaryotic genomes, and the effectiveness with which epigenetic (DNA and histone) modifications affect transcription of such repetitive mobile elements and DNAs adjacent to them. ${ }^{29-31}$

The first transposable element to be discovered in bacteria, found about a dozen years after McClintock's discoveries, was bacteriophage $\mathrm{Mu}$-an extraordinary temperate phage of $E$. coli that inserts nearly at random during lysogenization, often causing insertion (loss of function) mutations in bacterial host genes. ${ }^{32}$ In addition, new transposition is needed for each cycle of $\mathrm{Mu}$ DNA replication during lytic growth. ${ }^{33}$

Small (typically $<2 \mathrm{~kb}$ ) insertion sequence (IS) elements were discovered a few years later as causes of spontaneous mutation in E. coli. ${ }^{34-36}$ Most IS elements contain only genes and sites needed for their own regulated transposition, and like $\mathrm{Mu}$, were intriguing as 
likely microbial counterparts of McClintock's maize elements. Superimposed on Mu's highly efficient transposition during lytic growth and during lysogenization were many features that seemed specific to its distinctive temperate phage life style. ${ }^{33}$ A possible evolutionary or mechanistic relatedness of its transposition to that of the much smaller IS elements seemed uncertain. Further studies of E. coli's IS elements were complicated because their movement to new sites is relatively rare, and because they do not, in themselves, confer any phenotype (for example, drug resistance) that could be selected easily and directly. These features had made it difficult before the recombinant DNA revolution to analyze mechanisms and regulation of IS element transposition. It is with this background that the discovery of resistance transposons seemed hugely exciting and important.

We next tested for possible transposition of kanamycin resistance determinants from $\lambda b b$ kan phages to the $E$. coli chromosome. This entailed $\lambda b b$ kan infections of a $\triangle a t t B$ bacterial strain (so that integration of $\lambda$ itself would be inefficient) under conditions that minimize host cell killing (high multiplicity, 30C), and selection for kanamycin resistant transductant colonies. More than half of such transductants formed using phages $\lambda b b$ kan-1 and $\lambda b b$ kan-2 (encoding NPTII, from JR67) were non lysogenic, and $\sim 1 \%$ of these transductants were auxotrophs, unable to grow on minimal glucose agar. ${ }^{1}$ This was interpreted as transposition of this kan determinant (soon to be called $\mathrm{Tn} 5^{37,38}$ ) from the $\lambda b b$ kan phage to various sites in the E. coli chromosome. ${ }^{1}$ In contrast all kanamycin resistant transductants formed by infection with $\lambda b b$ kan-3 (NPTI from JR72) were lysogenic, suggesting that this putative element (soon to be called $\operatorname{Tn} 6^{37,38}$ ) was not nearly as active as $\operatorname{Tn} 5$, at least under our experimental conditions. These early tests illustrated the value of a selectable marker for transposable element studies. Given Tn5's apparently higher transposition efficiency and stability, most of our further studies focused on this element. ${ }^{39,40}$

\section{APRÈS GENÈVE: WITH JULIAN IN MADISON AND THE YEARS THAT FOLLOWED}

Given the overwhelming excitement and significance of our first Tn5 transposition results, I soon set aside plans for further $\lambda \mathrm{dv}$ replication and regulation studies, to focus on transposition. Julian had kindly offered me a temporary position in his group at the University of Wisconsin, Madison, and arranged with Howard Temin to provide me with financial support from a virology training grant. This allowed me to spend another $\sim 18$ productive, very beneficial and enjoyable months with him and his group. In Madison I continued my Tn5 studies and also benefited from his and his group's knowledge of antibiotics and the biochemistry, ecology and evolution of resistance determinants.

In Julian's group I generated a phage for high efficiency Tn5 transposition to the bacterial chromosome by recombining the Tn5 insertion in $\lambda b b$ kan- 2 into a $\lambda$ phage with a $\Delta b 221$ deletion; this deletion removes the phage attP site and thereby prevents $\lambda$ itself from integrating into host chromosomes far more effectively than is possible using $\triangle a t t B$ E. coli strains. Using this $\lambda \Delta b 221 \mathrm{Tn} 5$ phage and an F'lac plasmid target, I found that Tn5 could insert into many different sites in representative genes (here $l a c Z$ and $l a c Y$ ), a result suggesting that Tn5 had very little target sequence specificity. ${ }^{41}$

Important new friendships and collaborations were also developed, and strengthened, especially by Julian's Friday afternoon 'Goodies' (a Welsh-American equivalent of TGIF, perhaps?), for example with Mori Yagisawa, Patrice Courvalin, Mike Haas and David Smith in Julian's group, and with Rich Jorgensen next door in Bill Reznikoff's group. I also enjoyed close interactions with other researchers at this great university, including phage molecular biology experts Waclaw Szybalski and Martha Howe, bacterial geneticist and RNA polymerase expert Carole Gross, and Epstein-Barr Virus biology expert Bill Sugden. In addition, Rich and I collaborated with Bernard Allet in Geneva in the physical mapping of $\operatorname{Tn} 10$, a tetracycline resistance transposon, ${ }^{42}$ one of the several other transposable elements that also emerged from our $\lambda b b$ infection-induction experiments in Geneva. Rich, and others in Bill's group in the years that followed, carried out many elegant, insightful and informative analyses of Tn5 structure, and mechanism and control of transposition. ${ }^{43,44}$

I moved from Julian's lab in April 1977 to set-up my own transposition research group in the microbiology department of Washington University Med School (St Louis). I remained as a faculty member in this superb department until retirement nearly 36 years later, when I moved to San Diego, California, and there joined the faculties of the University of California San Diego and San Diego State University. The several decades following Tn5's discovery saw immense growth in understanding of many different transposable elements in prokaryotes and eukaryotes alike. Fundamental insights were gained into the numerous transposable element families; webs of relatedness and divergence of various elements; the multiple mechanisms of transposition and of regulating transposition; the effects of mobile DNA elements on genome structure, function and evolution; the resemblance between some transposition mechanisms and other specific DNA change phenomena such as immunoglobulin gene rearrangement and retrovirus integration; and the various ways in which transposable elements can be exploited as potent tools for diverse molecular genetic applications. My group and that of my sister, the late Claire Berg at University of Connecticut, were happy making important contributions to this body of knowledge with Tn5 and a few other bacterial elements, ${ }^{39,40}$ although I also decided in the early 1990 s to shift my research focus to the gastric pathogen Helicobacter pylori. Many of the most important advances in understanding Tn5 transposition and its regulation came from Bill Reznikoff and group. Especially in the $\sim 15$ years before his retirement in 2007 from the University of Wisconsin, Bill and his group made particularly insightful and important contributions to understanding Tn5's unique transposition mechanism and its regulation, and further developed Tn5 as a potent and tool for molecular genetic manipulation and analysis. ${ }^{44,45}$ Some key aspects of our understanding of $\operatorname{Tn} 5$ transposition and its uses are summarized below, and also more fully in multiple reviews, ${ }^{39,43,44}$ including a review that compares and contrasts $\operatorname{Tn} 5$ with $\operatorname{Tn} 10$, a distant member of the same transposon family. ${ }^{46}$

\section{Tn5 functional organization}

Tn5 is a composite transposon whose $1.5 \mathrm{~kb}$ inverted repeats are separately mobile elements (each called IS50). Partially related $19 \mathrm{bp}$ sequences at each IS50 or Tn5 end constitute sites of transposase action. Given a supply of transposase, any modest sized DNA segment between such $19 \mathrm{bp}$ sites in inverted orientation can be transposed. One of Tn5's IS50 elements encodes transposase, the only protein needed for Tn5 or IS50 transposition. The same reading frame also encodes a shorter transposition inhibitor protein, but from a downstream transcription promoter. The resulting inhibitor protein contains transposase's C-terminal dimerization domain but not transposase's N-terminal domain, which binds Tn5's and IS50's $19 \mathrm{bp}$ ends. The other IS50 element contains a mutant allele of the transposase/inhibitor gene, inactivated by a point mutation that created the promoter for expression of the NPTII kanamycin resistance gene in $\mathrm{Tn} 5$ 's unique central region (loop in Figures la and b). 
Downstream of the NPTII gene are two genes considered cryptic in standard E. coli lab strains, but that are expressed in certain other bacterial strains and species: a bleomycin resistance gene, which also increases bacterial fitness even when no bleomycin is present, and a streptomycin phosphotransferase (resistance) gene.

Tn5 transposition mechanism

Tn 5 transposes by a DNA breakage and joining mechanism without DNA replication (except for 9 base repair syntheses at each Tn5-target DNA junction). We had proposed this non-replicative break-join mechanism based on genetic data. ${ }^{41,47,48}$ Many workers, however, became captivated by early findings that phage $\mathrm{Mu}$ and $\mathrm{Tn} 3$ move by a fully replicative mechanism, ${ }^{49}$ and initially discounted our interpretation, perhaps because they implicitly sought a single unified mechanism of transposable element movement. Nevertheless, further detailed biochemical analyses showed absolutely that Tn5/IS50 elements transpose by a break-join mechanism, and provided a very detailed molecular understanding of it. ${ }^{43,44}$ Additional studies of other mobile DNA elements revealed other, mechanistically distinct break-join transposition processes. $^{50}$

\section{Regulation}

Tn5 /IS50 transposition is down-regulated in multiple ways that are thought to be advantageous in allowing low level transposition, which increases transposon copy number (despite its non-replicative breakjoin mechanism $)^{44}$ (transposons are considered 'selfish DNAs'), while minimizing risks of deleterious and lethal insertion mutations in host genomes. Factors that limit transposition include the following: (i) action of the inhibitor protein mentioned above; (ii) DNA adenine methylation (Dam) of the transposase promoter, which diminishes transcription during most of the cell cycle of the transposase gene, but not the embedded inhibitor gene, thereby helping link transposition to DNA replication; (iii) preferential action by transposase on Tn5/IS50 DNA ends very close to the gene encoding it, whereas inhibitor does not exert any such 'cis effect'; (iv) a requirement for Tn5/IS50 end DNA-stimulated dimerization of transposase for it to mediate transposition; (v) transposase and $19 \mathrm{bp}$ recognition site sequences that are less than maximally active; (vi) inability to translate the transposase open reading frame from readthrough transcripts from adjacent highly expressed genes; and (vii) a greater stability of inhibitor than of transposase protein. ${ }^{44}$

\section{In vitro transposition}

Transposition of Tn5-related elements is now easily accomplished totally in vitro, simply with a DNA substrate (critical $19 \mathrm{bp}$ at each IS50 end flanking DNA segment of interest), target DNA and purified transposase in a $\mathrm{Mg}++$ dependent reaction. Transposition can also be accomplished by electroporation of a transposase-transposon complex into target cells. No protein other than transposase is needed for transposition in vitro. Mutant transposases and modified IS50 termini that greatly improve the efficiency of transposition have been selected. ${ }^{44,45}$

\section{Tn5 as a tool for molecular genetics}

The high efficiency (relative to other elements) and simplicity, and low transposition target site specificity of Tn5/IS50 elements led to their extensive use as very potent tools for molecular genetic analysis and manipulation. Many Tn5-type elements had been engineered for specific purposes since, at the limit, only a pair of $19 \mathrm{bp}$ Tn5/IS50 end sequences flanking any DNA of interest is needed for transposition. Prominent uses and specific applications include: (i) making genetically marked knockout mutations by insertion into genes; (ii) providing engineered beta galactosidase, alkaline phosphatase or other reporter genes to monitor transcription, mRNA translation and protein localization; (iii) providing a regulated promoter to turn on adjacent gene expression at will; (iv) providing a mobile origin of plasmid DNA replication or DNA transfer by conjugation; (v) providing mobile primer binding sites and barcodes for DNA sequencing. Traditionally these various transposons were delivered from suicide vectors, such as a plasmid that could be transferred into but not replicated in target bacterial cells or with the integration-defective temperate phage $\lambda b 221$ cI857 mentioned above. ${ }^{40}$ However, the development by Bill Reznikoff and group of a high efficiency in vitro transposition system with optimized mutant transposase and IS50 end sequences freed us from the need for suicide vectors, and from complications of features noted above that normally limit transposition efficiency. ${ }^{44}$ This development opened up great new possibilities for transposon-based molecular genetic analysis and manipulation, in particular because of commercialization. Reagent kits for constructing Tn5 derivatives with essentially any needed features, and protocols and reagents for using such elements in efficient in vitro transposition reactions with desired target DNAs, or for electroporation of 'transposomes' (transposon-transposease DNA-protein complexes) into target cells are now available commercially. ${ }^{45}$

\section{Tn5's RESISTANCE GENES: APPLICATIONS}

Superimposed on the high value of Tn5-derived transposable elements summarized above, Tn5's NPT II gene, and also often the NPT I gene from transposons such as $\mathrm{Tn} 6$ or Tn903, have become widely used as selectable markers for diverse molecular genetic experiments and applications-both in microbes (typically involving kanamycin or neomycin resistance $)^{51,52}$ and in eukaryotes (involving resistance to G418 (geneticin), an aminoglycoside that is toxic to eukaryotic cells). ${ }^{53-55}$ The resistance Tn5's ble gene confers against bleomycin, a toxic antitumor glycopeptide, has also been used occasionally for selection in eukaryotes and in prokaryotes. ${ }^{56,57}$

\section{CONTINUING IMPACT AND INFLUENCE}

Summarized above are some of the positive, long-term impacts on biomedical research of Julian's creative insights and ideas about mechanisms and evolution of drug resistance, and of my great good fortune to have worked with him for a few years in Geneva and Madison. The lessons and perspectives I gained from our interactions continued to influence my research after I changed focus in the early 1990s, to begin studies of pathogenic bacteria, primarily the genetically diverse gastric pathogen $H$. pylori. This Gram-negative species chronically infects some half of all people worldwide, disproportionately in developing countries, typically for decades, and is a major cause of peptic ulcer disease and gastric cancer. ${ }^{58-60}$

\section{H. pylori's TRANSPOSABLE ELEMENTS}

It was difficult to completely ignore mobile DNA elements, to forgo the excitement of serendipitous discovery and preliminary characterization of new elements, after nominally shifting my research focus to H. pylori. In particular, in analyzing genomes of diverse $H$. pylori strains from various human populations, Dange Kersulyte and I were intrigued to discover two novel IS families: one, represented by the elements IS605, IS606, ISHp608 (or IS608) and ISHp609 (or IS609), whose movement is driven by a very small, novel tyrosine-type transposase; ${ }^{61-63}$ and second, IS607, that encodes a novel serine-type transposase. ${ }^{64}$ We found IS608 to be the most active of these in E. coli, and were pleased to send it to Mick Chandler, an expert in studies of 
diverse mobile elements (and a friend who also had been with Lucien in Geneva). Mick and his collaborator Fred Dyda at NIH and their groups showed elegantly that IS608 undergoes transposition by a most unusual break-join mechanism in which just one DNA strand is peeled off the donor site and pasted into recipient DNA at a specific $4 \mathrm{bp}$ target sequence, where it is presumed to be copied to restore intact double-stranded DNA. This 'peel and paste' mechanism is fundamentally distinct from other transposition mechanisms (break-join or replicative) that have been analyzed. ${ }^{65}$

Another serendipitous discovery emerging from our $H$. pylori genome analyses was that of the $\sim 40 \mathrm{~kb} \mathrm{TnPZ}$ conjugative transposons. Although these elements are rather variable in gene content and arrangement, many contain genes associated epidemiologically with virulence. Their putative transposase, 'XerT', belongs to an unusual branch of the XerC/ XerD family, whose protein members are best known for mediating recombination specifically at the terminus of bacterial chromosome replication and thereby helping ensure segregation of intact fully replicated chromosomes to daughter cells at division. In contrast, however, XerT appears to cause cognate transposon insertion at and duplicate a specific $7 \mathrm{bp}$ target sequence, which is found at many sites in a bacterial chromosome. ${ }^{66}$ We look forward eagerly to detailed molecular analyses of the TnPZ transposition mechanism.

\section{DRUG RESISTANCE IN $\boldsymbol{H}$. pylori}

Julian's impact on me was also evident in my keen interest in AR phenomena in H. pylori. Unfortunately, H. pylori strains resistant to metronidazole and clarithromycin (erythromycin), two of the most clinically useful anti- $H$. pylori drugs, are extremely common ( $>50 \%$ in some populations). Unlike many bacterial taxa, however, resistance in $H$. pylori is rarely if ever attributable to plasmid or transposon-borne resistance genes-even though many strains carry mobile DNA elements, and DNA exchange and recombination between strains is extremely common in Nature. Rather, all characterized resistances to clinically useful antibiotics seem to be due to mutation in normal $H$. pylori genes. In collaboration with Paul Hoffman, we found that resistance to metronidazole is due to inactivation of one or more nonessential nitroreductase genes that, when functional, cause conversion of metronidazole to bactericidal and mutagenic hydroxylamine type compounds. ${ }^{67-69}$ In addition, we and others showed that resistance to erythromycin-related macrolides, which is also common, stems from a point mutation at any of several sites in $23 \mathrm{~S}$ ribosomal RNA genes; and that tetracycline resistance, which is rare, typically involves a cluster of substitution mutations in its $16 \mathrm{~S}$ ribosomal RNA target. ${ }^{70-72}$

\section{AR GENES IN DEVELOPING COUNTRY LOW-INCOME SETTINGS}

As a final illustration of Julian's impact on me, I was pleased to help Washington University colleague Gautam Dantas and his students set-up collaborations with my long-term collaborators in Peru (Bob Gilman) and El Salvador (Teresita Bertoli) to examine the 'resistomes' in a peri-urban low-income community in Lima, Peru and in a Salvadorean agricultural community. Many resistance genes were found, were widely disseminated, and were often tightly associated with transposase- or phage integrase-like sequences. ${ }^{73}$ This points once again to a likely role of mobile DNA elements in dissemination of resistance in bacterial populations. ${ }^{73}$ Would I have studied drug resistance in $H$. pylori and/or embraced a study with Gautam on developing country resistomes had I not worked with and learned so much from Julian? Quite possibly not.

\section{AMINOGLYCOSIDES, SEQUENCE RELATIONSHIPS OF THEIR PHOSPHOTRANSFERASES AND EVOLUTIONARY IMPLICATIONS}

More than four decades have passed since Julian and Raoul Benveniste interpreted antibiotic modification specificity data as indicating an evolutionary relationship between antibiotic modifying genes of antibiotic producing organisms and the resistance genes often found in bacterial pathogens. ${ }^{14}$ Many thousands of aminoglycoside phosphotransferase genes have been discovered in diverse microbial taxa since then and have been sequenced. It is very satisfying that phylogenetic analyses of encoded phosphotransferase protein sequences shows strong intermingling of those from pathogens and antibiotic producing organisms, and thereby strong support for their ideas about the spread and evolution of resistance genes. Intriguing, although distant, relatedness of aminoglycoside phosphotransferases to protein kinases are also evident. ${ }^{74,75}$ These findings suggested that ancestral kinase genes whose products could be active on aminoglycosides may have preceded the emergence of aminoglycoside biosynthesis pathways and that such genes co-evolved with the capacity for aminoglycoside biosynthesis in antibiotic producing phyla, from which they spread to pathogens and other non-producing bacterial phyla and further evolved. ${ }^{74}$

Left somewhat uncertain, however, are the actual roles of aminoglycosides and other antibiotics of genes mediating their modifications in Nature's hugely complex multispecies bacterial communities. A traditional and widely accepted view for many of us was based on competition between strains and species potentially able to occupy the same niche, and the great advantage an antibiotic-producing (and resistant) microbe should enjoy when its metabolite inhibits or kills its competitors. This would be in accord with competitive advantages enjoyed by bacteria that make other bacteriocidal agents such as bacteriocin proteins ${ }^{76,77}$ and effectors delivered with type VI secretion systems. ${ }^{77,78}$ However, for more than a decade, Julian and collaborators have drawn attention to evidence that sub-lethal concentrations of antibacterial agents often cause interesting, and often probably advantageous, changes in patterns of bacterial gene expression and development. From this they argue that a major role in Nature of modest concentrations of these 'antibacterials' may actually be for non-lethal, indeed beneficial, communication and cooperation, and for the management of behavior of other cells in complex mixed populations. ${ }^{5,79}$ This would be akin to the actions of other bacterial metabolites used specifically for quorum sensing. ${ }^{80-82}$ If one embraces Julian's idea of antibiotics as mediators of cell-cell communication, it is interesting also to consider aminoglycoside phosphotransferases potentially serving as modulators of such signaling pathways-much as kinases that act on key regulatory proteins can profoundly alter cellular and developmental signaling networks. ${ }^{83-86}$ Julian's challenge to us, to rethink just what roles antibiotics may play in Nature, illustrates yet once again his creativity, his clarity of thought, his biochemical and evolutionary insights, and why it was such an immense pleasure and privilege to work with him in Geneva and Madison some four decades ago.

\section{CONFLICT OF INTEREST}

The author declares no conflict of interest.

\section{ACKNOWLEDGEMENTS}

First, my huge gratitude to Julian Davies for his kind collaboration, lessons, perspectives and generous hospitality when we worked closely together in the 1970s, and for his continuing friendship in the years that followed. Immense thanks are also due to many others for friendship, inspiration and contributions 
to the research summarized above-among them: (i) Jean-David Rochaix and Bernard Allet for their enthusiastic and inspired curiosity and collaboration with Julian and myself, and for their analyses that gave unequivocal evidence of Tn5 transposition; (ii) the late great Drosophila geneticist and teacher Larry Sandler, who, in his lectures to us grad students at the University of Washington in the 1960s, insisted that we read and think about Barbara McClintock's papers describing her mysterious transposable controlling elements, difficult as her purely genetic (pre-molecular) analyses were for us to understand-with a conviction that her ideas and mobile elements would become ever more interesting, important and understandable in the years to come; (iii) Dale Kaiser, with whom I post doc'd and learned about phage $\lambda$, and who kindly supported my interest in $\lambda d v$-for his critical but kind and gentle demeanor, and also for his including me on his family hikes in California's exquisite high Sierras, hikes often enriched with discussions about science and life; (iv) the late Lucien Caro, who kindly arranged for me to join him in Geneva, supported my continuing interest in $\lambda d v$, taught me many things about quantitative science, et partagé avec moi sa jouissance de la vie et de la culture francaise (and shared with me his enjoyment of French life and culture); (v) the late Grete Kellenberger-Gujer, my close collaborator in $\lambda d v$ studies in Lucien's group, for her wisdom, enthusiasm and perspectives, et aussi pour sa patience pendant que j'essayais. d'apprendre le français et de l'utiliser dans les discussions au labo (and also for her patience while I tried to learn French and use it in lab discussions); (vi) my sister, the late Claire M. Berg, for her perspectives and lessons in biology and genetics, even when I was a little kid, and for collaboration in transposon studies; (vii) Dangeruta Kersulyte, my wife and superb collaborator in studies of Helicobacter genomes and their transposable elements; and (viii) my students and other associates, friends and colleagues, whose efforts and insights yielded many important and interesting findings, and who gave me great pleasure and excitement during my decades at Washington University. I also thank Mori Yagisawa for suggesting a Tn5-centered tribute to Julian, and for his valuable comments on this manuscript; and the US National Institutes of Health, US National Science Foundation, and the American Cancer Society for generous research support over the years.

1 Berg, D. E., Davies, J., Allet, B. \& Rochaix, J. D. Transposition of R factor genes to bacteriophage lambda. Proc. Natl Acad. Sci. USA 72, 3628-3632 (1975).

2 Berg D. E. \& Howe M. M. (eds). Mobile DNA (American Society for Microbiology, Washington, DC, USA, 1989).

3 Davies, J. Microbes have the last word. A drastic re-evaluation of antimicrobial treatment is needed to overcome the threat of antibiotic-resistant bacteria. EMBO Rep. 8, 616-621 (2007)

4 Davies, J. \& Davies, D. Origins and evolution of antibiotic resistance. Microbiol. Mol. Biol. Rev. 74, 417-433 (2010).

5 Strachan, C. R. \& Davies, J. Antibiotics and evolution: food for thought. J. Ind Microbiol. Biotechnol. 43, 149-153 (2016).

6 Davies, J. Specialized microbial metabolites: functions and origins. J. Antibiot. (Tokyo) 66, 361-364 (2013)

7 Davies, J. Gathering no moss. Annu. Rev. Microbiol. 57, 1-27 (2003).

8 Matsubara, K. \& Kaiser, A. D. Lambda $d v$ : an autonomously replicating DNA fragment. Cold Spring Harb. Symp. Quant. Biol. 33, 769-775 (1968).

9 Berg, D. E. Genetic evidence for two types of gene arrangements in new lambda $d v$ plasmid mutants. J. Mol. Biol. 86, 59-68 (1974)

10 Berg, D. E. Genes of phage lambda essential for lambda $d v$ plasmids. Virology 62, 224-233 (1974).

11 Kellenberger-Gujer, G., Boy de la Tour, E. \& Berg, D. E. Transfer of the lambda $d v$ plasmid to new bacterial hosts. Virology 58, 576-585 (1974).

12 Berg, D. E. \& Kellenberger-Gujer, G. N protein causes the lambda $d v$ plasmid to inhibit heteroimmune phage lambda imm434 growth and stimulates lambda $d v$ replication. Virology 62, 234-241 (1974).

13 Citi, S. \& Berg, D. E. Grete Kellenberger-Gujer: molecular biology research pioneer Bacteriophage 6, e1173168 (2016)

14 Benveniste, R. \& Davies, J. Aminoglycoside antibiotic-inactivating enzymes in actinomycetes similar to those present in clinical isolates of antibiotic-resistant bacteria. Proc. Natl Acad. Sci. USA 70, 2276-2280 (1973).

15 Huang, A. S. Defective interfering viruses. Annu. Rev. Microbiol. 27, 101-117 (1973)

16 Berg, D. E. in The Bacteriophage Lambda (ed Hershey, A. D.) 667-678 (Cold Spring Harbor Press, Cold Spring Harbor, NY, USA, 1971).

17 Berg, P. \& Mertz, J. E. Personal reflections on the origins and emergence of recombinant DNA technology. Genetics 184, 9-17 (2010).
18 Chang, A. C. \& Cohen, S. N. Genome construction between bacterial species in vitro: replication and expression of Staphylococcus plasmid genes in Escherichia coli. Proc. Natl Acad. Sci. USA 71, 1030-1034 (1974).

19 Jackson, D. A., Symons, R. H. \& Berg, P. Biochemical method for inserting new genetic information into DNA of Simian Virus 40: circular SV40 DNA molecules containing lambda phage genes and the galactose operon of Escherichia coli. Proc. Natl Acad. Sci. USA 69, 2904-2909 (1972).

20 Berg, D. E., Jackson, D. A. \& Mertz, J. E. Isolation of a lambda $d v$ plasmid carrying the bacterial gal operon. J. Virol. 14, 1063-1069 (1974).

21 Shimada, K., Weisberg, R. A. \& Gottesman, M. E. Prophage lambda at unusual chromosomal locations. I. Location of the secondary attachment sites and the properties of the lysogens. J. Mol. Biol. 63, 483-503 (1972).

22 Umezawa, H., Doi, O., Ogura, M., Kondo, S. \& Tanaka, N. Phosphorylation and inactivation of kanamycin by Pseudomonas aeruginosa. J. Antibiot. (Tokyo) 21, 154-155 (1968).

23 Okanishi, K., Kondo, S., Utahara, R. \& Umezawa, H. Phosphorylation and inactivation of aminoglycosidic antibiotics by $E$. coli carrying R factor. J. Antibiot. (Tokyo) 21 13-21 (1968)

24 Yagisawa, M. et al. A new enzyme in Escherichia coli carrying R-factor phosphorylating 3'-hydroxyl of butirosin A, kanamycin, neamine and ribostamycin. J. Antibiot. (Tokyo) 25, 748-750 (1972)

25 Brzezinska, M. \& Davies, J. Two enzymes which phosphorylate neomycin and kanamycin in Escherichia coli strains carrying R factors. Antimicrob. Agents Chemother 3, 266-269 (1973)

26 McClintock, B. The origin and behavior of mutable loci in maize. Proc. Natl Acad. Sci. USA 36, 344-355 (1950).

27 McClintock, B. Controlling elements and the gene. Cold Spring Harb. Symp. Quant. Biol. 21, 197-216 (1956).

$28 \mathrm{McClintock}, \mathrm{B}$. The significance of responses of the genome to challenge. Science $\mathbf{2 2 6}$ 792-801 (1984).

29 Feng, S., Jacobsen, S. E. \& Reik, W. Epigenetic reprogramming in plant and animal development. Science 330, 622-627 (2010).

30 Levin, H. L. \& Moran, J. V. Dynamic interactions between transposable elements and their hosts. Nat. Rev. Genet. 12, 615-627 (2011).

31 Sundaram, V. et al. Widespread contribution of transposable elements to the innovation of gene regulatory networks. Genome Res. 24, 1963-1976 (2014).

32 Taylor, A. L. Bacteriophage-induced mutation In Escherichia coli. Proc. Natl Acad. Sci. USA 50, 1043-1051 (1963).

33 Harshey, R. M. Transposable Phage Mu. Microbiol. Spectr. 2, MDNA3-0007-2014 (2014).

34 Michaelis, G., Saedler, H., Venkov, P. \& Starlinger, P. Two insertions in the galactose operon having different sizes but homologous DNA sequences. Mol. Gen. Genet. 104, 371-377 (1969).

35 Saedler, H. \& Heiss, B. Multiple copies of the insertion-DNA sequences IS1 and IS2 in the chromosome of E. coli K-12. Mol. Gen. Genet. 122, 267-277 (1973).

36 Shapiro, J. A. Mutations caused by the insertion of genetic material into the galactose operon of Escherichia coli. J. Mol. Biol. 40, 93-105 (1969).

37 Campbell, A. et al. in DNA Insertion Elements, Plasmids and Episomes (eds Bukhari, A. I., Shapiro, J. A., Adhya S. L.) 15-22 (Cold Spring Harbor Press, Cold Spring Harbor, NY, USA, 1977).

38 Campbell, A. et al. Nomenclature of transposable elements in prokaryotes. Gene $\mathbf{5}$, 197-206 (1979).

39 Berg, D. E. in Mobile DNA (eds Berg, D. E. \& Howe, M. M.) 185-210 (American Society for Microbiology, Washington, D.C., USA, 1989).

40 Berg, C. M., Berg, D. E., Groisman, E. in Mobile DNA (eds Berg, D. E. \& Howe, M. M.) 879-925 (American Society for Microbiology, Washington, D.C., USA, 1989).

41 Berg, D. E. in DNA Insertion Elements, Plasmids and Episomes (eds Bukhari, A. I., Shapiro, J. A. \& Adhya, S. L.) 205-212 (Cold Spring Harbor Press, Cold Spring Harbor, NY, USA, 1977).

42 Jorgensen, R. A., Berg, D. E., Allet, B. \& Reznikoff, W. S. Restriction enzyme cleavage map of Tn 10, a transposon which encodes tetracycline resistance. J. Bacteriol. 137, 681-685 (1979).

43 Reznikoff, W. T. in In Mobile DNA II (eds Craig, N., Craigie, R., Gellert, M. \& Lambowitz, A.) 403-422 (American Society for Microbiology, Washington, D.C., USA, 2002).

44 Reznikoff, W. S. Transposon Tn5. Annu. Rev. Genet. 42, 269-286 (2008).

45 Epicentre: EZ-Tn5TM Transposase. http://www.epibio.com/enzymes/in-vivo-transposomics-/ez-tn5-transposase?details. Accessed on 26 August 2016.

46 Haniford, D. B. \& Ellis, M. J. Transposons Tn10 and Tn5. Microbiol. Spectr. 3 MDNA3 0002-2014 (2015).

47 Davies, J., Courvalin, P. \& Berg, D. Thoughts on the origins of resistance plasmids. J. Antimicrob. Chemother. 3(Suppl C): 7-17 (1977).

48 Berg, D. E. Structural requirement for IS50-mediated gene transposition. Proc. Nat Acad. Sci. USA 80, 792-796 (1983).

49 Shapiro, J. A. Molecular model for the transposition and replication of bacteriophage $\mathrm{Mu}$ and other transposable elements. Proc. Natl. Acad. Sci. USA. 76, 1933-1937 (1979).

50 Siguier, P., Gourbeyre., E., Varani, A., Ton-Hoang, B. \& Chandler, M. Everyman's Guide to Bacterial Insertion Sequences. Microbiol. Spectr 3, MDNA3-0030-2014 (2015).

51 Stibitz, S. Use of conditionally counterselectable suicide vectors for allelic exchange. Methods Enzymol. 235, 458-465 (1994).

52 Taylor, D. E. Genetics of Campylobacter and Helicobacter. Annu. Rev. Microbiol. 46 35-64 (1992). 
53 Sugden, B., Yates, J. \& Mark, W. Transforming functions associated with Epstein-Barr virus. J. Invest. Dermatol. 83(Suppl): 82s-87s (1984).

54 Datta, K. \& Datta, S. K. Indica rice (Oryza sativa, BR29 and IR64). Methods Mol. Biol. 343, 201-212 (2006).

55 Wang, T. T., Choi, Y. J. \& Lee, B. H. Transformation systems of non-Saccharomyces yeasts. Crit. Rev. Biotechnol. 21, 177-218 (2001).

56 Messina, M., Niesman., I., Mercier, C. \& Sibley., L. D. Stable DNA transformation of Toxoplasma gondii using phleomycin selection. Gene 165, 213-217 (1995).

57 Guerrero, C., Mateos, L. M., Malumbres, M. \& Martín, J. F. The bleomycin resistance gene of transposon Tn5 is an excellent marker for transformation of corynebacteria. Appl. Microbiol. Biotechnol. 36, 759-762 (1992).

58 Marshall, B. J. \& Windsor, H. M. The relation of Helicobacter pylori to gastric adenocarcinoma and lymphoma: pathophysiology, epidemiology, screening, clinical presentation, treatment, and prevention. Med. Clin. North Am. 89, 313-344 (2005).

59 Cooke, C. L., Torres, J. \& Solnick, J. V. Biomarkers of Helicobacter pylori-associated gastric cancer. Gut Microbes 4, 532-540 (2013).

60 Arnold, M. et al. The burden of stomach cancer in indigenous populations: a systematic review and global assessment. Gut 63, 64-71 (2014).

61 Kersulyte, D., Akopyants, N. S., Clifton, S. W., Roe, B. A. \& Berg, D. E. Novel sequence organization and insertion specificity of IS605 and IS606: chimaeric transposable elements of Helicobacter pylori. Gene 223, 175-186 (1998).

62 Kersulyte, D. et al. Transposable element ISHp608 of Helicobacter pylori: nonrandom geographic distribution, functional organization, and insertion specificity. J. Bacteriol. 184, 992-1002 (2002).

63 Kersulyte, D. et al. Sequence organization and insertion specificity of the novel chimeric ISHp609 transposable element of Helicobacter pylori. J. Bacteriol. 186, 7521-7528 (2004).

64 Kersulyte, D., Mukhopadhyay, A. K., Shirai, M., Nakazawa, T. \& Berg, D. E. Functional organization and insertion specificity of IS607, a chimeric element of Helicobacter pylori. J. Bacteriol. 182, 5300-5308 (2000).

$65 \mathrm{He}$, S. et al. The IS200/IS605 family and 'Peel and Paste' single-strand transposition mechanism. Microbiol. Spectr 3, 0039-2014 (2015).

66 Kersulyte, D. et al. Helicobacter pylori's plasticity zones are novel transposable elements. PLoS ONE 4, e6859 (2009).

67 Jeong, J. Y. et al. Sequential inactivation of $r d x A$ (HP0954) and frxA (HP0642) nitroreductase genes causes moderate and high-level metronidazole resistance in Helicobacter pylori. J. Bacteriol. 182, 5082-5090 (2000).

68 Sisson, G. et al. Metronidazole activation is mutagenic and causes DNA fragmentation in Helicobacter pylori and in Escherichia coli containing a cloned $\mathrm{H}$. pylori $\mathrm{RdxA}(+)$ (Nitroreductase) gene. J. Bacteriol. 182, 5091-5096 (2000).
69 Jeong, J. Y. et al. Roles of FrxA and RdxA nitroreductases of Helicobacter pylori in susceptibility and resistance to metronidazole. J. Bacteriol. 183, 5155-5162 (2001).

70 Morris, J. M. et al. Evaluation of seaFAST, a rapid fluorescent in situ hybridization test, for detection of Helicobacter pylori and resistance to clarithromycin in paraffinembedded biopsy sections. J. Clin. Microbiol. 43, 3494-3496 (2005).

71 Nahar, S. et al. Antimicrobial susceptibility of Helicobacter pylori strains isolated in Bangladesh. J. Clin. Microbiol. 42, 4856-4858 (2004).

72 Dailidiene, D. et al. Emergence of tetracycline resistance in Helicobacter pylori: multiple mutational changes in $16 \mathrm{~S}$ ribosomal DNA and other genetic loci. Antimicrob. Agents Chemother. 46, 3940-3946 (2002).

73 Pehrsson., E. C. et al. Interconnected microbiomes and resistomes in low-income human habitats. Nature 533, 212-216 (2016).

74 Wright, G. D. \& Thompson, P. R. Aminoglycoside phosphotransferases: proteins, structure, and mechanism. Front. Biosci. 4, D9-21 (1999).

75 Daigle, D. M., McKay, G. A., Thompson, P. R. \& Wright, G. D. Aminoglycoside antibiotic phosphotransferases are also serine protein kinases. Chem. Biol. 6, 11-18 (1999).

76 Riley, M. A. \& Gordon, D. M. The ecological role of bacteriocins in bacterial competition. Trends Microbiol. 7, 129-133 (1999).

77 Jamet, A. \& Nassif, X. New players in the toxin field: polymorphic toxin systems in bacteria. MBio 6, e00285-15 (2015).

78 Cianfanelli, F. R., Monlezun, L. \& Coulthurst, S. J. Aim, load, fire: the type VI secretion system, a bacterial nanoweapon. Trends Microbiol. 24, 51-62 (2016).

79 Yim, G., Wang, H. H. \& Davies, J. The truth about antibiotics. Int. J. Med. Microbiol. 296, 163-170 (2006).

80 Kendall, M. M. \& Sperandio, V. What a dinner party! mechanisms and functions of interkingdom signaling in host-pathogen associations. MBio 1, e01748 (2016).

81 Waters, C. M. \& Bassler, B. L. Quorum sensing: cell-to-cell communication in bacteria. Annu. Rev. Cell. Dev. Biol. 21, 319-346 (2005).

82 Camilli, A. \& Bassler, B. L. Bacterial small-molecule signaling pathways. Science $\mathbf{3 1 1}$ 1113-1116 (2006).

83 Manning, G., Whyte, D. B., Martinez, R., Hunter, T. \& Sudarsanam, S. The protein kinase complement of the human genome. Science 298, 1912-1934 (2002).

84 Tarrant, M. K. \& Cole, P. A. The chemical biology of protein phosphorylation. Annu. Rev. Biochem. 78, 797-825 (2009).

85 Hunter, T. The genesis of tyrosine phosphorylation. Cold Spring Harb. Perspect. Biol. 6, a020644 (2014).

86 Thorner, J., Hunter, T., Cantley, L. C. \& Sever, R. Signal transduction: From the atomic age to the post-genomic era. Cold Spring Harb. Perspect. Biol. 6, a022913 (2014) 